\title{
In-vitro characterization and evaluation of mesoporous titanium dioxide composite hydroxyapatite and its effectiveness in occluding dentine tubules
}

\author{
Lu Yin ${ }^{1,2}$, Xuehong Xu ${ }^{1,2}$, Chienyu Chu ${ }^{1,2}$, Pingting Lin ${ }^{1,2}$, Honglan Huang ${ }^{1,2}$, Bizhu Luo ${ }^{1,2}$ and Changwei Yang ${ }^{1,2^{*}}$
}

\begin{abstract}
Background: To synthesize mesoporous titanium dioxide composite hydroxyapatite $\left(\mathrm{TiO}_{2}-\mathrm{HAP}\right)$ and to evaluate its effectiveness in sealing of occluding dentine tubules.

Methods: $\mathrm{TiO}_{2}-\mathrm{HAP}$ was synthesized by chemical precipitation method and characterized using infrared absorption spectrometer, X-ray diffraction, scanning electron microscope, and specific surface area detector. Forty completely extracted molars were prepared and randomly assigned into Control group, Gluma group, $\mathrm{HAP}$ group and $\mathrm{TiO}_{2}-\mathrm{HAP}$ group according to different treatments. The characteristics of $\mathrm{HAP}$ and $\mathrm{TiO}_{2}-\mathrm{HAP}$ and the sealing effectiveness of dentine tubules in these four groups, including infrared spectrum, surface contact angle, pore size distribution, and re-mineralized enamel surface profiles, were analyzed by suitable characterized techniques. The cytotoxicity of the synthesized $\mathrm{TiO}_{2}-\mathrm{HAP}$ was tested and compared using 3-(4,5)-dimethylthiahiazo(-z-y1)-3,5-di-phenytetrazoliumromide (MTT) colorimetry.
\end{abstract}

Results: Our results showed $\mathrm{TiO}_{2}-\mathrm{HAP}$ group had significantly lower contact angle, higher specific surface area, and wider range of pore size distribution than other groups. The majority of dentinal tubules in the TiO $2-\mathrm{HAP}_{2}$ group were blocked by white matter in a uniformed manner, and the crystals arranged in order grew along the axial direction. In addition, no significant difference in optical density (OD) value was found between control group and $\mathrm{TiO}_{2}-\mathrm{HAP}$ group ( $P>0.05$ ), and cell growth was good in $\mathrm{TiO}_{2}-\mathrm{HAP}$ group, indicating no cytotoxicity of $\mathrm{TiO}_{2}-\mathrm{HAP}$.

Conclusions: The MTT assay identified that $\mathrm{TiO}_{2}-\mathrm{HAP}$ had little effect on the $\mathrm{L} 929$ cell line. We showed $\mathrm{TiO}_{2}-\mathrm{HAP}$ might be used as a remineralization agent in enamel caries-like lesions.

Keywords: Titanium dioxide, Hydroxyapatite, Dentin hypersensitivity, Occlusion

\section{Background}

Dentine hypersensitivity (DH) is a significant public oral health concern with a severe consequence to individual social life, psychological status, and/or discomfort from

\footnotetext{
*Correspondence: yl_yin@sina.cn

${ }^{1}$ Xiamen Key Laboratory of Stomatological Disease Diagnosis

and Treatment, Stomatological Hospital of Xiamen Medical College, No.

1309, Lvling Road, Huli District, Xiamen 361008, Fujian, China

Full list of author information is available at the end of the article
}

pain, affecting over $43 \%$ of adult's population globally [1]. The underlying mechanism for $\mathrm{DH}$ actions is still awaiting investigation, and the widely accepted hydrodynamic theory suggested that fluid movement along the dentin tubules resulted from external stimuli activates the terminals of the pulp and cause pain [2]. In this scenario, occlusion of dentin tubules by natural or artificial materials might be an effective approach in the treatment of $\mathrm{DH}$ 
since it could render the movement of intratubular flows through mechanical manner [3].

A large variety of different occlusion materials, such as hydroxyapatite (HAP), potassium oxalates, sodium fluoride, calcium glycerophosphate, and abrasive agents, have been investigated for the treatment of $\mathrm{DH}$ in oral care industry [4]. Among which, nanohydroxyapatite, as one of the most biocompatible and bioactive materials, has extensively been applied in dentistry due to its favorable properties such as similarities to the mineral phase of the human hard tissues, biocompatibility, and low solubility in humid environments [5]. Indeed, it has been suggested in previous study that nanohydroxyapatite could be applied to repair dental enamel and treat DH [6].

In addition, as an n-type semiconductor, mesoporous titanium dioxide $\left(\mathrm{TiO}_{2}\right)$ has extensive applications in photocatalysis and conversion of solar energy because of its high refractive index, wide band gap, chemical stability, and low cost [7]. With the structure of hollow spheres, $\mathrm{TiO}_{2}$ have attracted extensive attention in the fields of catalysis, microreactors, adsorption, and drug delivery [7]. For instance, the large fraction of void space in hollow structures has been successfully used to encapsulate and control release of sensitive materials such as drugs, cosmetics, and DNA [8]. Therefore, we proposed that incorporating HAP into nanoscale mesoporous $\mathrm{TiO}_{2}$ composite (mesoporous $\mathrm{TiO}_{2}$ composite HAP, $\mathrm{TiO}_{2}-\mathrm{HAP}$ ) using chemical precipitation method might produce a fabricate biomaterial with suitable surface to volume ratio, antibacterial action, physical, mechanical, biological characteristics, and distinctive particle size, which renders it effective vehicles for dental applications. The characteristics of $\mathrm{TiO}_{2}-\mathrm{HAP}$ and HAP, and their occluding effectiveness of dentine tubules were analyzed by suitable characterized techniques.

\section{Methods}

Materials

Calcium nitrate $\left(\mathrm{Ca}\left(\mathrm{NO}_{3}\right)_{2}\right)$, potassium nitrate $\left(\mathrm{KNO}_{3}\right)$, and ammonia $\left(\mathrm{NH}_{3} \cdot \mathrm{H}_{2} \mathrm{O}\right)$ were purchased from Guoyao Chemical Reagent Co., Ltd. (Shanghai, China). Diammonium hydrogen phosphate $\left(\left(\mathrm{NH}_{4}\right)_{2} \mathrm{HPO}_{4}\right)$ was purchased from Xilong Chemical Co., Ltd. (Shantou, China). X-ray diffractometer $(D / \max R B)$ was obtained from Japanese Neo Confucianism motor. Infrared absorption spectrometer (SPECTRO LAB M11) was obtained from SPEK analytical instruments Co., Ltd. Scanning electron microscope (SEM)/energy dispersive spectrometer (JSM-6510) and transmission electron microscope (JEM-1400plus) were bought from Japan Electronics Co., Ltd. Specific surface area detector (F-Sorb 2400) was obtained from Beijing Kingaipu Technology Co., Ltd. HAP composites containing mesoporous $\mathrm{TiO}_{2}$ and HAP materials without $\mathrm{TiO}_{2}$ were both self-made.

\section{Preparation of $\mathrm{TiO}_{2}-\mathrm{HAP}$}

Mesoporous $\mathrm{TiO}_{2}-\mathrm{HAP}$ was synthesized by chemical precipitation method as previously described [3]. In general, $5 \mathrm{ml}$ tetrabutyl titanate (TBOT), $2 \mathrm{ml}$ acetylacetone and $3.14 \mathrm{mg}$ stearic acid were mixed and stirred for $30 \mathrm{~min}$ to obtain the TBOT complex, which was then slowly dispersed into $40 \mathrm{ml}$ deionized water under the condition of rapid stirring, and a milky yellow dispersion system was formed by continuously stirring for $30 \mathrm{~min}$. The dispersion system was then transferred to three polytetrafluoroethylene reactors with a volume of $25 \mathrm{ml}$, and then reacted in water for $10 \mathrm{~h}$ at $150{ }^{\circ} \mathrm{C}$. The products were centrifugally washed with distilled water and absolute ethanol, respectively. Finally, the product was dried in an oven at $80^{\circ} \mathrm{C}$ for $6 \mathrm{~h}$ to obtain $\mathrm{TiO}_{2}-\mathrm{HAP}$.

\section{Preparation of molar teeth samples}

Forty molars were collected and the residual soft tissue around the teeth was removed. The teeth were cleaned by ultrasonic cleaning and stored in $0.1 \%$ thymol solution at $4{ }^{\circ} \mathrm{C}$. Perpendicular to the long axis of the tooth, the root was excised about $2 \mathrm{~mm}$ away from the enamel cementum boundary root. The enamel of occlusal surface was completely removed and dentin was exposed. After wetting the dentin surface, the dentin surface was polished with silicon carbide water sandpaper to prepare a standard bonding surface of $3 \mathrm{~mm} \times 3 \mathrm{~mm} \times 2 \mathrm{~mm}$, and ultrasonic cleaning was performed for $10 \mathrm{~min}$. The surface of teeth was dried and divided into control group, Gluma group, HAP group and $\mathrm{TiO}_{2}-\mathrm{HAP}$ group (10 sample/ group) (Table 1). The sealing effect was observed under scanning electron microscope (SEM) when the samples were coated and placed for 1 week.

\section{Characterization of $\mathrm{TiO}_{2}-\mathrm{HAP}$ and other materials Infrared spectroscopy analysis}

To analyze the chemical components of samples, the infrared spectra were measured using a Perkin Elmer Universal ATR spectrometer to identify the functional group constituents of $\mathrm{TiO}_{2}-\mathrm{HAP}$ and HAP.

\section{$X$-ray diffraction analysis}

The X-ray diffraction (XRD) analysis was performed to observe the possible changes in phase between the different samples. The XRD patterns were recorded using a diffractometer (PANalytical-Empyrean instrument. Co.) and analyzed between 0 and $90{ }^{\circ} \mathrm{C}$ ( 2 theta). The voltage, current and pass time used were $40 \mathrm{kV}, 40 \mathrm{~mA}$ and $1 \mathrm{~s}$, respectively.

\section{High-resolution transmission electron microscopic analysis}

The morphology of the prepared samples was observed under a high-resolution transmission electron 
Table 1 Sample grouping and preservation conditions

\begin{tabular}{lll}
\hline Groups & Treatment method & Preservation conditions \\
\hline $\begin{array}{ll}\text { Control group } \\
\text { Gluma group }\end{array}$ & $\begin{array}{l}\text { The sample surface was not treated } \\
\text { Dry the sample, dip it in Gluma desensitizer, and smear the sample }\end{array}$ & After being embedded in wax, it was stored at $37^{\circ} \mathrm{C}$ for 7 days \\
HAP group & $\begin{array}{l}\text { Dry the sample, dip it in } \mathrm{HAP} \text { desensitizer, and smear the sample } \\
\text { surface repeatedly for } 10 \mathrm{~min}\end{array}$ \\
$\mathrm{TiO}_{2}-\mathrm{HAP}$ group & $\begin{array}{l}\text { Dry the sample, dip it in } \mathrm{TiO}_{2}-\mathrm{HAP} \text { desensitizer, and smear the sam- } \\
\text { ple surface repeatedly for } 10 \text { min }\end{array}$ \\
\hline
\end{tabular}

microscope (HRTEM; Philips CM 120 model) according to the published article [4].

\section{F-Sorb 2400 surface area analyzer}

According to the Brunauer Emmett Teller equation theory and the Barrett Joyner Halenda method, the specific surface area and total pore volume of HAP and $\mathrm{TiO}_{2}-\mathrm{HAP}$ were measured by F-Sorb 2400 surface area analyzer with the exhaust temperature of $120{ }^{\circ} \mathrm{C}$ and the degassing time of $45 \mathrm{~min}$ [9]. Because of the very small diameter of nitrogen molecule, nitrogen adsorption method was used. It was measured by the inherent droplet method. A micropipette was used to take $0.5 \mu \mathrm{l}$ of the liquid onto the surface of the four samples. After $5 \mathrm{~s}$, each sample can be photographed and recorded at three optional points. Then change the specimen and test liquid in turn. After developing the film, enlarge the photo by 3.5 times and measure the contact angle of each time with a goniometer. The average contact angle of three points of each specimen was taken as the contact angle of this specimen. According to the contact angle, the surface energy was calculated by Mathematica 4.1 software package.

\section{MTT colorimetric method}

The specimens were cleaned with absolute ethanol for 20 min, washed with distilled water, sterilized at $121{ }^{\circ} \mathrm{C}$ and $33 \mathrm{MPa}$, and dried in an oven. Then the specimen was placed in a glass bottle and $20 \mathrm{ml}$ normal saline was added at $37{ }^{\circ} \mathrm{C}$ for $72 \mathrm{~h}$. The MTT colorimetric method was carried out according to the Chinese national standard GB/T 16886.5-1997 biological evaluation of medical devices cytotoxicity test in vitro method. The OD mean value $(n=6)$ of each group was calculated. Cell proliferation percentage $(\mathrm{RGR} \%)=(\mathrm{OD}$ mean value of each concentration group/OD mean value of negative control group) $\times 100 \%$. According to Table 2 , the RGR\% of each concentration group of the extract was converted into $0-5$ grade cytotoxicity.
Table 2 Corresponding relationship between cell proliferation percentage and cytotoxicity grade

\begin{tabular}{ll}
\hline RGR\% & Cytotoxicity grade \\
\hline$\geq 100$ & Grade 0 \\
$75-99$ & Grade 1 \\
$50-74$ & Grade 2 \\
$25-49$ & Grade 3 \\
$0-24$ & Grade 4 \\
0 & Grade 5 \\
\hline
\end{tabular}

\section{Statistical analysis}

Statistical analysis was made by software Statistical Product and Service Solutions (SPSS) version 17.0 (International Business Machines, corp., Armonk, NY, USA). Significant differences between groups were assessed by One-way analysis of variance (ANOVA). This was followed by a multi-comparison test with Bonferroni correction $(\alpha=0.05)$. All data were expressed as means \pm standard deviation (SD). Differences were considered statistically significant when $P<0.05$.

\section{Results}

Sample characterization and dentin surface energy analysis

As shown in Fig. 1, the infrared absorption at 1042, 605 and $560 \mathrm{~cm}^{-1}$ of the $\mathrm{TiO}_{2}-\mathrm{HAP}$ was consistent with the standard spectrum of HAP. The absorption peaks at $605 \mathrm{~cm}^{-1}$ and $560 \mathrm{~cm}^{-1}$ were obviously superimposed on the envelope peaks at $500-700 \mathrm{~cm}^{-1}$, which indicated that the sample contains both $\mathrm{HAP}$ and $\mathrm{TiO}_{2}$. Moreover, as shown in Table 3 and Fig. 2, the contact angles in Gluma, HAP and $\mathrm{TiO}_{2}-\mathrm{HAP}$ groups were significantly decreased than that in the control group in Double distilled water and Diiodiomethane $(P<0.05)$.

Specific surface area of $\mathrm{TiO}_{2}-\mathrm{HAP}$

The specific surface area in $\mathrm{TiO}_{2}-\mathrm{HAP}$ group was $124.65 \pm 23.24 \mathrm{~m}^{2} / \mathrm{g}$, and that in HAP group was $74.01 \pm 11.68 \mathrm{~m}^{2} / \mathrm{g}$. The total pore volume in $\mathrm{TiO}_{2}-$ HAP group was $0.23 \mathrm{~cm}^{3} / \mathrm{g}$, and that in HAP group 

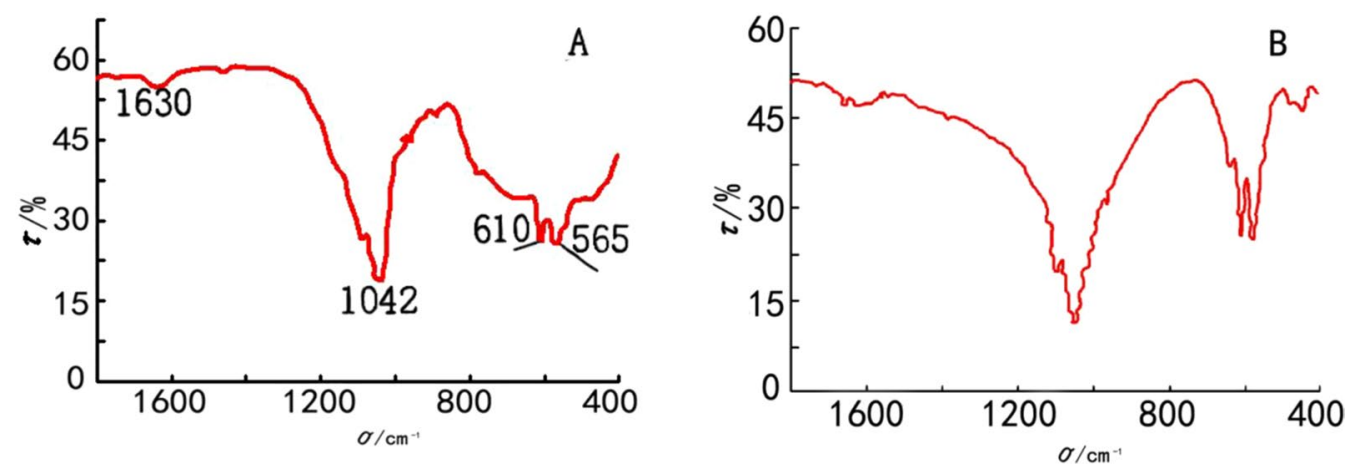

Fig. 1 Infrared spectrum. a $\mathrm{TiO}_{2}-\mathrm{HAP}$; b hydroxyapatite

Table 3 Surface contact angle and surface free energy values

\begin{tabular}{|c|c|c|c|c|c|}
\hline \multirow[t]{2}{*}{ Groups } & \multicolumn{2}{|l|}{ Contact angle $\left(\theta^{\circ}\right)$} & \multicolumn{3}{|c|}{ Surface free energy $\left(\mathrm{nJ} / \mathrm{cm}^{2}\right)$} \\
\hline & Double distilled water & Diiodiomethane & $\gamma_{\mathrm{s}}$ & $\gamma_{s}^{d}$ & $\gamma_{s}^{p}$ \\
\hline Control group & $68.78 \pm 12.15$ & $55.14 \pm 10.34$ & $44.19 \pm 1.36$ & $30.44 \pm 0.65$ & $13.75 \pm 0.34$ \\
\hline Gluma group & $50.78 \pm 9.14^{*}$ & $29.75 \pm 7.16^{*}$ & $48.24 \pm 3.56$ & $20.40 \pm 0.54$ & $23.84 \pm 0.68$ \\
\hline HAP group & $40.86 \pm 18.16^{*}$ & $32.91 \pm 8.43^{*}$ & $59.70 \pm 3.27$ & $47.53 \pm 0.66$ & $12.17 \pm 0.54$ \\
\hline $\mathrm{TiO}_{2}-\mathrm{HAP}$ group & $32.78 \pm 7.14^{*}$ & $38.75 \pm 5.16^{*}$ & $46.24 \pm 3.36$ & $25.60 \pm 0.87$ & $20.64 \pm 0.73$ \\
\hline
\end{tabular}

A1

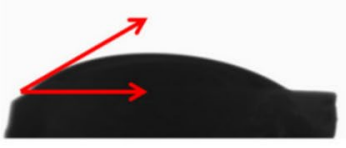

A2

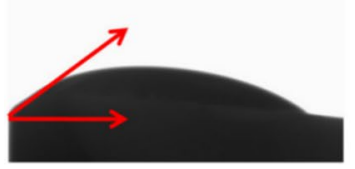

B1

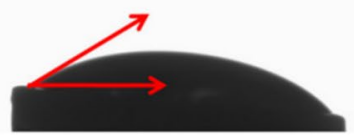

B2

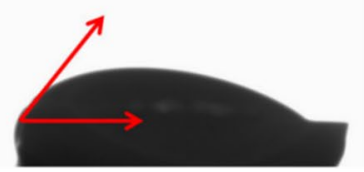

C1

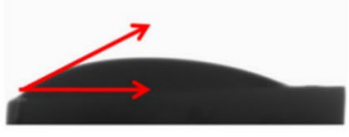

C2

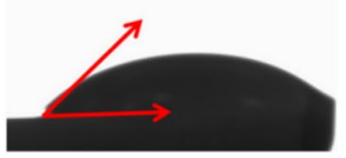

D1

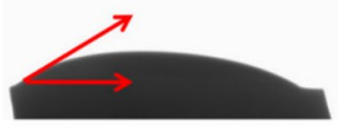

D2

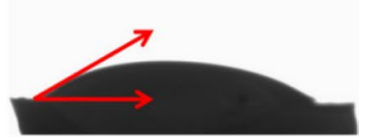

Fig. 2 The values of contact angle. a Control group; $\mathbf{b}$ Gluma group; $\mathbf{c} \mathrm{HAP}$ group and $\mathbf{d} \mathrm{TiO}_{2}-\mathrm{HAP}$ group

was $0.17 \mathrm{~cm}^{3} / \mathrm{g}$. Moreover, the volume pore size distribution of HAP was in the range of $0-30 \mathrm{~nm}$, and that of $\mathrm{TiO}_{2}-\mathrm{HAP}$ was $0-50 \mathrm{~nm}$, indicating wider range of pore size distribution after forming composite (Fig. 3).

\section{Analysis of enamel surface morphology}

As shown in Fig. 4, SEM imaging showed that the dentin tubules were clearly visible, and the opening of the tubules was oval with a diameter of $1-5 \mu \mathrm{m}$, and the mineralization degree of periodontal dentin was higher than that of inter tubal dentin in the control group. The dentin was covered with a layer of material, and most of the canaliculi were blocked, and the diameter of the tubule orifice was significantly smaller with smooth surface in Gluma group than that in the control group. Most of the dentinal tubules were sealed by a layer of white matter, and there was a gap between the white matter and the dentin tubules, and some of the dentin tubules were 

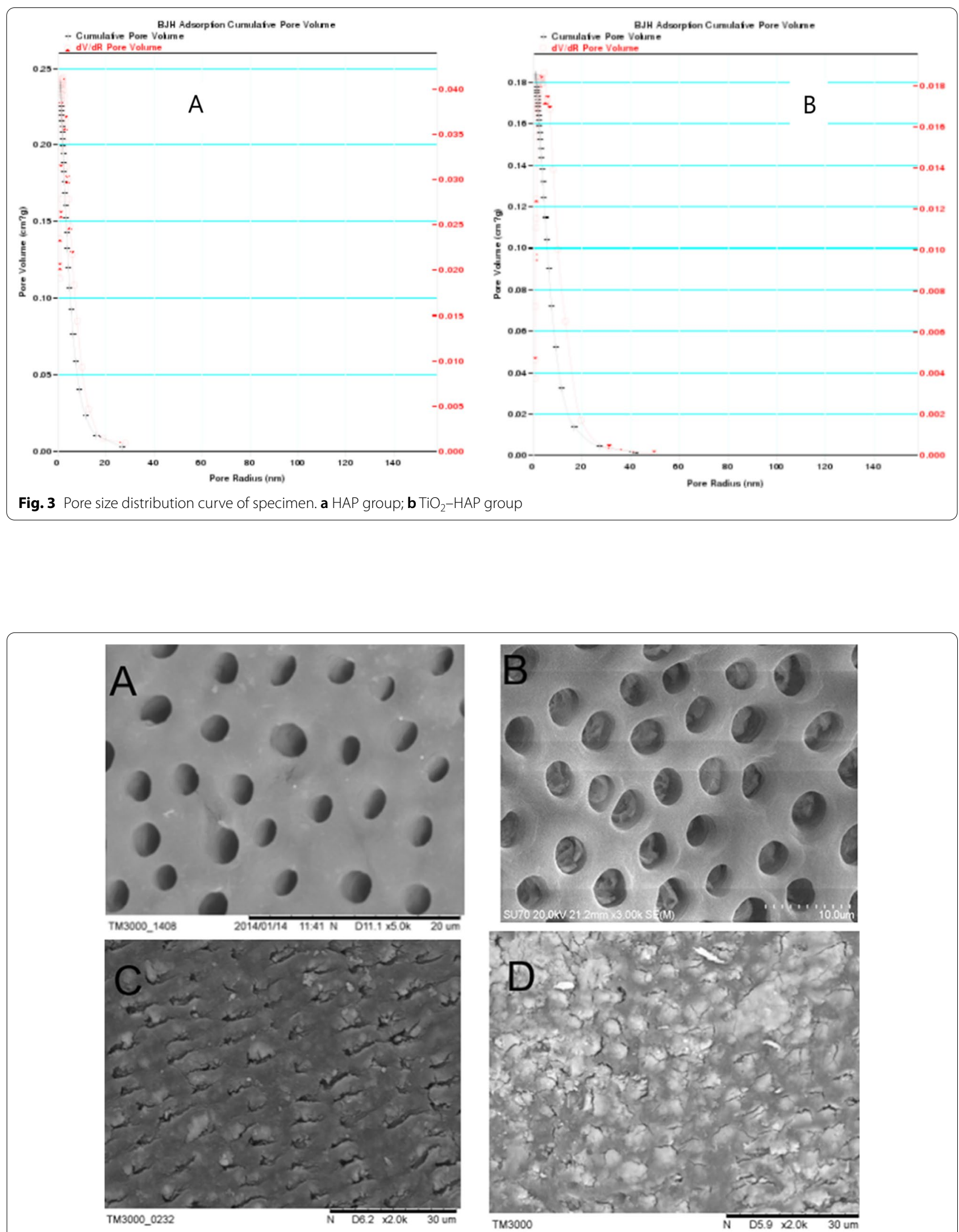

Fig. 4 Enamel surfaces of the four groups after remineralization. a Control group; b Gluma group; $\mathbf{c} \mathrm{HAP}$ group and $\mathbf{d} \mathrm{TiO}_{2}-\mathrm{HAP}$ group 
not well sealed in the HAP group. Almost all the dentinal tubules were blocked by white matter, and the distribution of white matter was uniform in the $\mathrm{TiO}_{2}-\mathrm{HAP}$ group.

\section{Analysis of enamel profile}

SEM imaging showed that the dentin tubules were arranged in a linear pattern and parallel to each other, and no substance was found at the opening of the dentin tubules with smooth wall in the control group (Fig. 5). The cross-sectional opening of the dentinal tubules was blocked by white matter, and the blockage was found in the dentin tubules, with a depth of about $11 \mu \mathrm{m}$ in the Gluma group. The cross-sectional opening of the dentinal tubules was blocked by white matter, and the penetration depth of the plug into the dentin tubules was about $24 \mu \mathrm{m}$ in the HAP group. The penetration depth of the plug into the dentin tubules was about $15 \mu \mathrm{m}$, and the ordered crystals grow along the dentin tubules in the $\mathrm{TiO}_{2}-\mathrm{HAP}$ group.

\section{Cytotoxicity}

As shown in Table 4, the OD values of $\mathrm{TiO}_{2}-\mathrm{HAP}$ groups with different concentration were both higher than that of positive group $(P<0.05)$. However, there was no significant difference in OD value between control group and $\mathrm{TiO}_{2}-\mathrm{HAP}$ group $(P>0.05)$. Moreover, the Cytotoxicity grades of control group and $\mathrm{TiO}_{2}-\mathrm{HAP}$ group were both Grade 0. As shown in Fig. 6, the cell morphology was good on the 4th day after cell culture in the control and $\mathrm{TiO}_{2}-\mathrm{HAP}$ groups. Moreover, the density of MTT crystal

Table 4 Cytotoxicity of $\mathrm{TiO}_{2}-\mathrm{HAP}$

\begin{tabular}{llll}
\hline Groups & OD values & RGR (\%) & $\begin{array}{l}\text { Cytotoxicity } \\
\text { grade }\end{array}$ \\
\hline Positive group & $0.006+0.00$ & 5 & 4 \\
Control group & $0.257+0.014^{*}$ & 100 & 0 \\
$75 \% \mathrm{TiO}_{2}-\mathrm{HAP}$ group & $0.286+0.032^{*}$ & 111 & 0 \\
$50 \% \mathrm{TiO}_{2}-\mathrm{HAP}$ group & $0.298+0.059^{*}$ & 115 & 0 \\
$25 \% \mathrm{TiO}_{2}-\mathrm{HAP}$ group & $0.266+0.041^{*}$ & 103 & 0 \\
$12.5 \% \mathrm{TiO}_{2}-\mathrm{HAP}$ group & $0.259+0.055^{*}$ & 100 & 0 \\
\hline
\end{tabular}

\section{${ }^{*} P<0.05$}

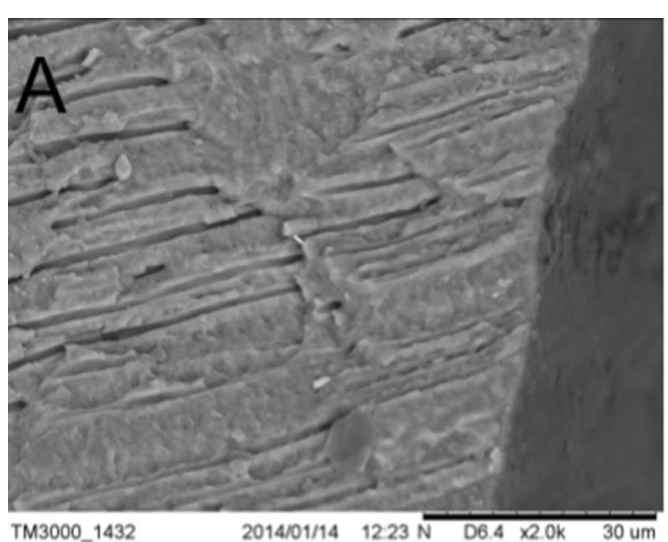

TM3000_1432

$2014 / 01 / 14 \quad 12.23 \mathrm{~N} \quad$ D6.4 $\times 2.0 \mathrm{~K} \quad 30 \mathrm{um}$

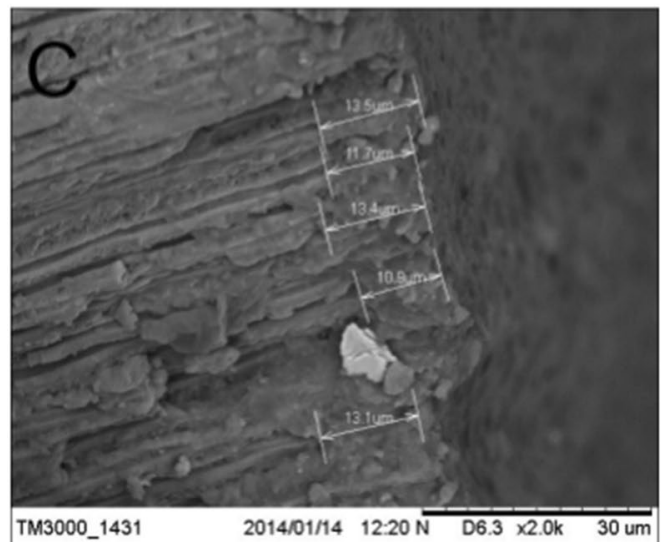

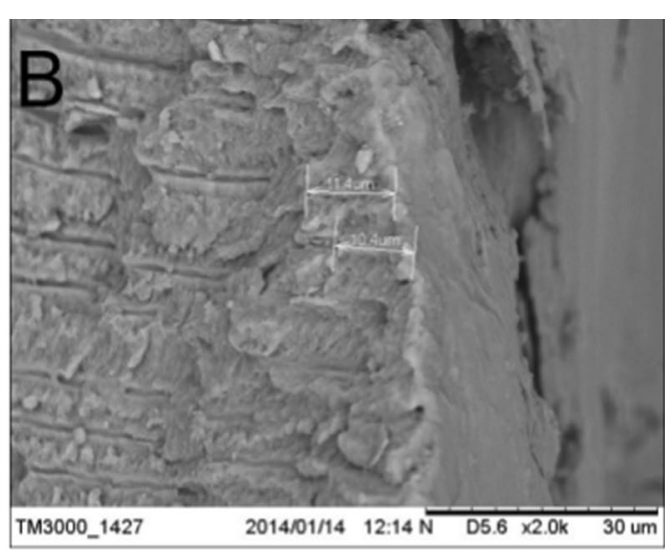

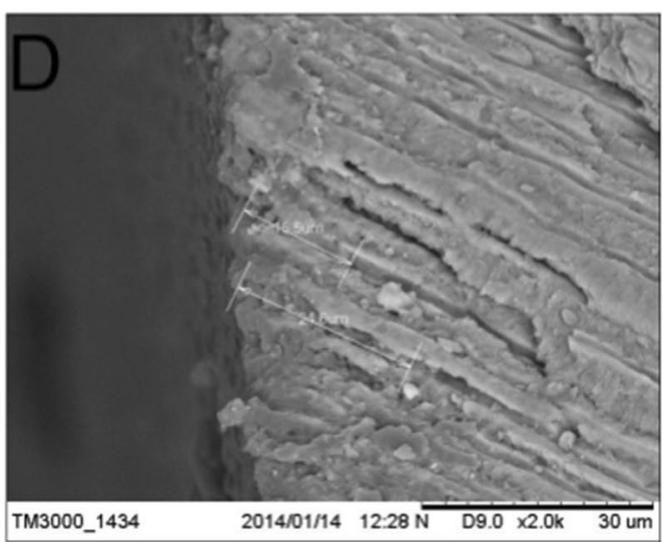

Fig. 5 Enamel profile of the four groups after remineralization. a Control group; b Gluma group; $\mathbf{c} \mathrm{HAP}$ group and $\mathbf{d} \mathrm{TiO}_{2}-\mathrm{HAP}$ group 

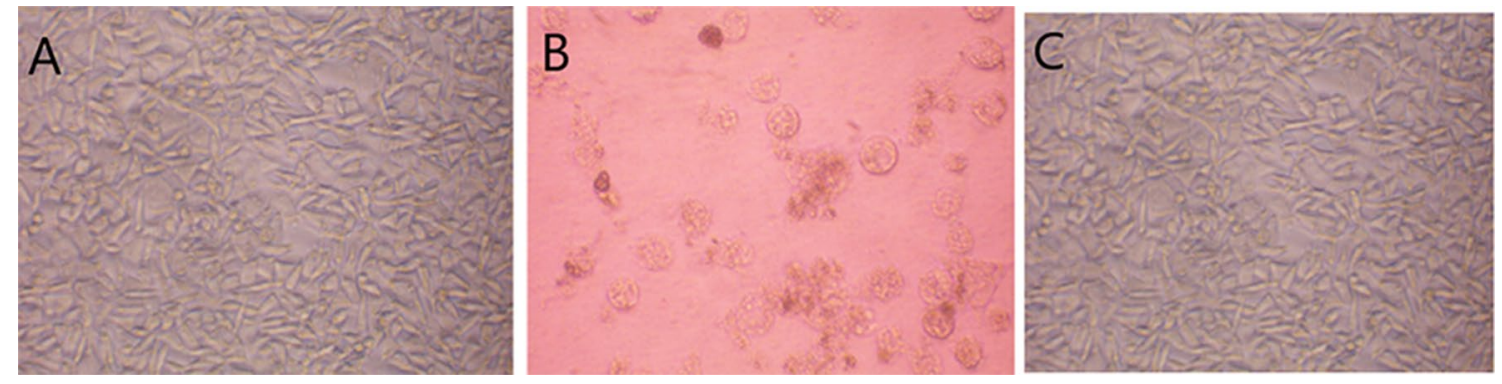

Fig. 6 The cell imaging on the 4 th day after cell culture. a Control group; b positive group; c $75 \% \mathrm{TiO}_{2}-\mathrm{HAP}$ group

in the $\mathrm{TiO}_{2}-\mathrm{HAP}$ group was similar to that of negative control group, showing a transparent blue purple color.

\section{Discussion}

Nanohydroxyapatite is widely incorporated in toothpaste to promote enamel remineralization as well as treat dentine hypersensitivity. In this study, we explored the effect of $\mathrm{TiO}_{2}-\mathrm{HAP}$ in occuluding dentin tubules by different techniques. Specific surface area and surface energy test methods were used to analyze composition and properties, and finally cytotoxicity experiments are used to verify its biological safety. Our results showed that $\mathrm{TiO}_{2}-$ HAP can occulude the micropores on the surface of dentin in vitro without cytotoxicity.

We firstly synthesized $\mathrm{TiO}_{2}-\mathrm{HAP}$ by chemical precipitation method, and the phase and chemical composition of HAP carbonate were analyzed by XRD and infrared absorption spectrometer. We found that the infrared absorption at 1042, 605 and $560 \mathrm{~cm}^{-1}$ of the $\mathrm{TiO}_{2}-\mathrm{HAP}$ was consistent with the standard spectrum of HAP. The absorption peaks at $605 \mathrm{~cm}^{-1}$ and $560 \mathrm{~cm}^{-1}$ were obviously superimposed on the envelope peaks at 500$700 \mathrm{~cm}^{-1}$, which indicated that the sample contains both $\mathrm{HAP}$ and $\mathrm{TiO}_{2}$ [10].

The surface wettability is related to the surface energy, and the surface contact angle can objectively reflect the surface energy of the object [11]. The surface contact angle is affected by many factors. The oral cavity is often at a constant temperature. The energy reflecting the surface properties of the material rarely changes with the surface elements, so the surface energy is a better indicator for the surface wettability in coating [12]. The smaller the surface contact angle, the greater the surface energy, and the better the wettability of the object. The liquid is easy to spread on the surface and the adhesive can effectively contact the surface of the tooth. Conversely, the larger the surface contact angle, the smaller the surface energy, the poorer the wettability of the object, and the less likely it is for liquid to spread on its surface and affect the adhesion. In our study, we found that the contact angle in the $\mathrm{TiO}_{2}-\mathrm{HAP}$ group was smaller than that in the HAP group. Those results indicated that the wettability of $\mathrm{TiO}_{2}-\mathrm{HAP}$ was good.

The specific surface area of HAP is mainly affected by the total pore volume or crystal size [13]. The total pore volume is the pore volume within a predetermined pore size range, which can be determined from adsorption or desorption curves [14]. The microporous structure and large specific surface area are conducive to the attachment of biological tissues. In the present study, the specific surface area and the total pore volume in the $\mathrm{TiO}_{2}-\mathrm{HAP}$ group were higher than those in the HAP group. It is suggested that $\mathrm{TiO}_{2}-\mathrm{HAP}$ is conducive to the attachment of biological tissues. In the past few years, the main attempt is not only to control the shape of HAP powder, but also to control the crystal size, particle size distribution, porosity and crystallinity, because they have great influence on mechanical properties and biological activity [11]. In this study, mesoporous titanium dioxide HAP was compounded. The mesopores caused lattice distortion, the worse degree of crystallinity, the smaller particle size, and the increased specific surface area. Due to the unique structural state of nanoparticles, surface effects are produced, so that nanomaterials exhibit special functions such as adsorption, catalysis and biological activity [15]. Moreover, we found that the range of pore size distribution of $\mathrm{TiO}_{2}-\mathrm{HAP}$ was increased. It may be due to that when the size of HAP reaches the nanometer level, it will show a series of unique properties, such as high degradability and absorbability [16].

We also analyzed the surface morphology of tooth enamel. We found that the dentin tubules in the control group were clearly visible, but that of the $\mathrm{TiO}_{2}-\mathrm{HAP}$ group was enclosed by white matter. The results showed that material in the control group only had a certain repair effect on the surface of the glaze pillars, and there was no improvement in a large number of glaze pillar gaps. HAP without mesoporous $\mathrm{TiO}_{2}$ can repair the etched surface. However, HAP mainly uses the adsorption properties of nanoparticles to fill the cavities on 
the enamel surface, so HAP can only form a loose mineralized layer on the enamel surface. After the flower like crystals were removed by ultrasonic wave, the gap between demineralized glazes was repaired well by $\mathrm{TiO}_{2}-\mathrm{HAP}$. There are a lot of mesoporous titania sheets in $\mathrm{TiO}_{2}-\mathrm{HAP}$ composites [17], which can cause excessive nucleation on the surface of enamel. During the process of crystal nucleation and growth, new nucleation sites are formed on the surface of enamel. These new nuclei continue to adsorb calcium and phosphorus ions in artificial saliva, grow radially and epitaxially, and finally form flower-like crystals.

Furthermore, we analyzed the profile of enamel. We found that in the $\mathrm{TiO}_{2}-\mathrm{HAP}$ group, the depth of occlusion was about $15 \mu \mathrm{m}$, and the orderly arranged crystals grew along the dentin tubules. This may be due to the fact that the negatively charged mesoporous titanium dioxide layer contained in the $\mathrm{TiO}_{2}-\mathrm{HAP}$ composite material can be combined with the positively charged HAP through electrostatic adsorption, which increases the orientation arrangement and adsorption binding force of $\mathrm{TiO}_{2}-\mathrm{HAP}$ composite particles in the demineralization zone. At the same time, the oxygen-containing functional groups on mesoporous titanium dioxide can effectively attract $\mathrm{Ca}^{2+}$ and $\mathrm{PO}_{3}{ }^{-4}$ ions from artificial saliva [18]. The orientation adsorption of HAP crystals existing in the remineralization solution and the in-situ growth of new HAP crystals interact with each other at the same time, which makes the dentin defect repaired well.

Moreover, we investigated whether $\mathrm{TiO}_{2}-\mathrm{HAP}$ exhibits cellular cytotoxicity in vitro after incubation of $\mathrm{TiO}_{2}-$ HAP with cells for 4 days, we observed long spindle and polygonal and circular dividing cells similar to the control group, indicating that the cell growth was vigorous and the cell had a strong refractive index. The results showed that $\mathrm{TiO}_{2}-\mathrm{HAP}$ had no cytotoxicity.

\section{Conclusion}

$\mathrm{TiO}_{2}-\mathrm{HAP}$ can seal the micropores on the surface of dentin in vitro. The composite has good porosity and high surface energy without obvious influence on resin binders. It has no cytotoxicity in biological safety testing. However, one potential limitation of the current study is that the durability of the coatings were not assessed, thus we could not analyze the long-term effect of $\mathrm{TiO}_{2}-\mathrm{HAP}$ in clinical study.

\section{Abbreviations}

$\mathrm{DH}$ : Dentine hypersensitivity; $\mathrm{TiO}_{2}-\mathrm{HAP}$ : Titanium dioxide composite hydroxyapatite; XRD: X-ray diffraction; SEM: Scanning electron microscope; $\mathrm{TiO}_{2}$ : Titanium dioxide; $\mathrm{Ca}\left(\mathrm{NO}_{3}\right)_{2}$ : Calcium nitrate; $\mathrm{KNO}_{3}$ : Potassium nitrate; $\mathrm{NH}_{3} \cdot \mathrm{H}_{2} \mathrm{O}$ : Ammonia; $\left(\mathrm{NH}_{4}\right)_{2} \mathrm{HPO}_{4}$ : Diammonium hydrogen phosphate; SD: Standard deviation.

\section{Acknowledgements}

None.

\section{Authors' contributions}

$\mathrm{LY}$ and $\mathrm{XHX}$ was the guarantor of integrity of the entire study. CWY designed the study. HLH contributed to the definition of intellectual content, experimental studies and data acquisition. CYC participated inliterature research and wrote the manuscript. PTL took part in the clinical studies. BZL analyzed the data and statics. All authors read and approved the final manuscript.

\section{Funding}

This study was supported by Education and scientific research for young and middle-age project in Fujian Province [Grant Number JAT190831], Open subject for Engineering Research Center of Fujian University for Stomatological Biomaterials [Grant Number XMMCKQ001] and Fujian health research talent training project-Youth Project [Grant Number 2019-2-56]. All these funding played no role in the design of the study and collection, analysis, and interpretation of data and in writing the manuscript.

\section{Availability of data and materials}

The datasets used or analysed during the current study are available from the corresponding author on reasonable request.

\section{Declarations}

\section{Ethics approval and consent to participate}

This study was approved by the Ethics Committee of Engineering Research Center of Fujian University for Stomatological Biomaterials. All patients gave informed written consent to participate in the study.

\section{Consent for publication}

Informed consent was obtained from all individual participants included in the study.

\section{Competing interests}

The authors declare that they have no competing interests.

\section{Author details}

${ }^{1}$ Xiamen Key Laboratory of Stomatological Disease Diagnosis and Treatment, Stomatological Hospital of Xiamen Medical College, No. 1309, Lvling Road, Huli District, Xiamen 361008, Fujian, China. ${ }^{2}$ Engineering Research Center of Fujian University for Stomatological Biomaterials, Xiamen 361008, Fujian, China.

Received: 7 December 2020 Accepted: 25 November 2021

Published online: 23 February 2022

References

1. Saeki K, Marshall GW, Gansky SA, Parkinson CR, Marshall SJ. Strontium effects on root dentin tubule occlusion and nanomechanical properties. Dent Mater. 2016;32(2):240-51.

2. Brännström $M$, Lindén $L$, Åström A. The hydrodynamics of the dental tubule and of pulp fluid. Caries Res. 1967;1:310-7.

3. Sykes L. Dentine hypersensitivity: a review of its aetiology, pathogenesis and management: clinical. S Afr Dent J. 2007:62:66-71.

4. Onwubu SC, Naidoo D, Mkhize SC, Mabaso NLN, Mdluli PS, Thakur S. An investigation in the remineralization and acid resistant characteristics of nanohydroxyapatite produced from eggshell waste via mechanochemistry. J Appl Biomater Funct Mater. 2020;18:1-8.

5. Huang SB, Gao SS, Yu HY. Effect of nano-hydroxyapatite concentration on remineralization of initial enamel lesion in vitro. Biomed Mater. 2009;4:034104.

6. Gjorgievska ES, Nicholson JW, Slipper IJ, et al. Remineralization of demineralized enamel by toothpastes: a scanning electron microscopy, energy dispersive $X$-ray analysis, and three-dimensional stereo-micrographic study. Microsc Microanal. 2013;19:587-95. 
7. Shang $\mathrm{SQ}$, Jiao $\mathrm{XL}$, Chen DR. Template-free fabrication of $\mathrm{TiO}_{2}$ hollow spheres and their photocatalytic properties. ACS Appl Mater Interfaces. 2012;4:860-5.

8. Lou XW, Archer LA, Yang ZC. Hollow micro-/nano-structures: synthesis and applications. Adv Mater. 2008;20:3987.

9. Wodarczyk-Stasiak M, Jamroz J. Specific surface area and porosity of starch extrudates determined from nitrogen adsorption data networks: effects on mineral coating morphology and growth kinetic. J Food Eng. 2009;93:379-85.

10. Junjie L, Hui Y, Yiping $C$, et al. Research progress of micro nano hydroxyapatite and its composites. Prog Chem Ind. 2006;25(6):651-7.

11. Wang A-J, Lu Y-P, Zhu R-F. Effect of sintering on porosity, phase, and surface morphology of spray dried hydroxyapatite microspheres. J Biomed Mater Res Part A. 2008;87:558-62.

12. Palizhati A, Zhong W, Tran $\mathrm{K}$, et al. Toward predicting intermetallics surface properties with high-throughput DFT and convolutional neural networks. J Chem Inf Model. 2019;59(11):4742-9.

13. Rajbhandari R, Shrestha LK, Pokharel BP, et al. Development of nanoporous structure in carbons by chemical activation with zinc chloride. J Nanosci Nanotechnol. 2013:13(4):2613-23.

14. Sigmund $G$, Hüffer $T$, Hofmann T, et al. Biochar total surface area and total pore volume determined by $\mathrm{N}_{2}$ and $\mathrm{CO}_{2}$ physisorption are strongly influenced by degassing temperature. Sci Total Environ. 2017;580:770-5.

15. Catros S, Guillemot F, Lebraud E. Physico-chemical and biological properties of a nano-hydroxyapatitepowder synthesized at room temperature. IRBM. 2010;31:226-33.

16. Kreyling WG, Semmler-Behnke M, Chaudhry Q. A complementary definition of nanomaterial. Nano Today. 2010;5:165-8.

17. Hu XJ, Liu JK, Lu Y, et al. Facile synthesis and characterization of hydroxylapatite nanoparticle chains. Mater Lett. 2008;62:3824-6.

18. Jin XD, Guo YW, Wang J, et al. The preparation of $\mathrm{TiO}_{2} /$ hydroxylapatite $\left(\mathrm{TiO}_{2} / \mathrm{HA}\right)$ composite and sonocatalytic damage to bovine serum albumin (BSA) under ultrasonic irradiation. J Mol Catal A Chem. 2011;341:89-96.

\section{Publisher's Note}

Springer Nature remains neutral with regard to jurisdictional claims in published maps and institutional affiliations.

Ready to submit your research? Choose BMC and benefit from:

- fast, convenient online submission

- thorough peer review by experienced researchers in your field

- rapid publication on acceptance

- support for research data, including large and complex data types

- gold Open Access which fosters wider collaboration and increased citations

- maximum visibility for your research: over $100 \mathrm{M}$ website views per year

At BMC, research is always in progress.

Learn more biomedcentral.com/submissions 